\section{ARTIGO}

Recebido em: 28/04/2017

Aceito em: 09/04/2018

\title{
A nova estrutura normativa de ciência, tecnologia e inovação no Brasil
}

\author{
The new normative structure of science, technology and innovation \\ in Brazil
}

\author{
Marcelo MINGHELLI (marcelo.minghelli@ufsc.br)* \\ * Professor do Departamento de Ciência da Informação - UFSC (PGCIN).
}

\section{Resumo}

O Ordenamento Jurídico Nacional tem passado por significativas mudanças, tentando acompanhar as transformações sociais e econômicas decorrentes dos processos de inovação tecnológica. Em dimensões diferentes, estas novas modificações tentam criar instrumentos legais para a implantação de um sistema de inovação, bem como para a proteção de direitos. Diante das importantes atualizações da atual estrutura normativa de Ciência, Tecnologia e Inovação no Brasil, este estudo tem como objetivo realizar uma análise crítica sobre a matriz, as concepções e objetivos que envolveram a estrutura mencionada e as suas características. Pretende-se a partir deste ensaio contribuir para o entendimento do atual contexto, analisando as bases teóricas que suportaram a sua implementação. No Brasil, a interface entre o setor público e o setor privado encontra obstáculos, muitos deles representados no ordenamento jurídico nacional que impede a articulação entre os dois setores, identificandoa como uma espécie de risco aos recursos públicos. É possível afirmar que a Emenda Constitucional n. 85/2015 e a Lei n. 13.243/2016 estipularam um modelo de sistema de inovação nacional caracterizado como um modelo de tripla hélice, mas estruturado a partir do Estado.

Palavras-chave: Inovação. Estado. Emenda Constitucional n85. Lei 13243/2016.

\begin{abstract}
The National Legal Order has undergone significant changes, trying to follow the social and economic transformations resulting from the processes of technological innovation. In different dimensions, these new modifications try to create legal instruments for the implementation of an innovation system, as well as for the protection of rights. Faced with the important updates of the current normative structure of Science, Technology and Innovation in Brazil, this study aims to perform a critical analysis about the matrix, the conceptions and objectives that involved the mentioned structure and its characteristics. This essay intends to contribute to the understanding of the current context, analyzing the theoretical bases that supported its implementation. In Brazil, the interface between the public sector and the private sector encounters obstacles, many of which are represented in the national legal system, which prevents the articulation between the two sectors, identifying it as a kind of risk to public resources. It is possible to affirm that the Constitutional Amendment n. 85/2015 and Law no. 13,243 / 2016 stipulated a model of a national innovation system characterized as a triple-helix model but structured from the State.
\end{abstract}

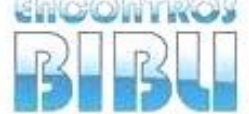

v. 23 , n. esp., 2018 p. $143-151$

ISSN 1518-2924

Keywords: Innovation. State. Constitutional Amendment n85. Law 13243 / 2016.

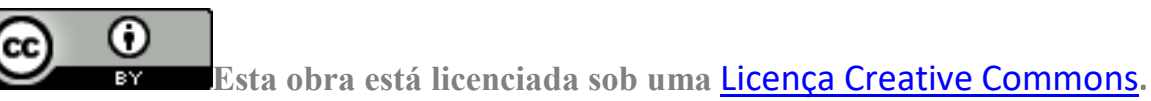




\section{INTRODUÇÃO}

O ordenamento Jurídico Nacional tem passado por significativas mudanças, tentando acompanhar as transformações sociais e econômicas decorrentes dos processos de inovação tecnológica. Em dimensões diferentes, estas novas modificações tentam criar instrumentos legais para a implantação de um sistema de inovação, bem como para a proteção de direitos.

Verifica-se assim que os direitos fundamentais, como a privacidade, têm sua proteção normativa ampliada constantemente pelo legislador. Mas, efetivamente os dispositivos normativos pouco ou nada significam diante da capacidade de surveillance da espionagem corporativa e das agências ligadas aos Estados com maior desenvolvimento tecnológico.

Conforme ocorrido com a maior empresa estatal brasileira quando teve informações confidenciais e estratégicas para o País vasculhadas pela National Security Agency (NSA). A resposta brasileira foi a elaboração do Marco Civil da Internet, que é considerado um instrumento normativo importante e concebido através de uma ampla participação popular. No entanto, este é insuficiente para a proteção dos interesses do Estado Brasileiro e de direitos fundamentais como o da privacidade.

No entanto, parece ingênuo pensar que uma norma seja capaz de frear ou equiparar os cidadãos ou mesmo um Estado com menor desenvolvimento tecnológico às grandes corporações ou às agências de inteligência como a NSA. A liberdade, a privacidade e a igualdade de condições nesse novo "território" internacional também devem ser protegidas pelo desenvolvimento e pela concomitante democratização de novas tecnologias.

Neste caso, tecnologias que possam, por exemplo, desvelar o processo de vigilância sobre os dados pessoais dos indivíduos ou impedir que interesses nacionais estratégicos sejam acessados. Para tanto, elas precisam ser desenvolvidas e o conhecimento precisa ser gerado, ou seja, não se trata apenas de normatizar, mas antes disso gerar conhecimento e tecnologia e aplicá-los em finalidades democráticas.

No âmbito deste contexto, a inovação não é apenas um processo fundamental para a economia do País, é também é um elemento essencial para a manutenção do Estado Democrático de Direito. A forma como se produz a inovação, como esta é apropriada e para o que será destinada é fundamental para definir os contornos da nova esfera pública, que agora é impactada pelas novas tecnologias e para sempre será modificada pelas consequências de suas utilizações.

Conforme defendem os economistas que estudam o desenvolvimento econômico, o avanço tecnológico de um país é a sua principal força motora. E esta afirmação não é recente, Marx (1867), Schumpeter (1911) já haviam defendido esta questão. Ao longo dos anos, estudos empíricos foram realizados para demonstrar através de dados o papel do progresso técnico no crescimento econômico, destacase os estudos de Solow (1957) e Denison (1962). Portanto, analisar os mecanismos nacionais de promoção ao desenvolvimento tecnológico torna-se importante para o aperfeiçoamento de políticas públicas voltadas ao incentivo, participação ativa dos diferentes stakeholders (empresas, governo, sociedade, etc.) e o entendimento do papel do Estado neste processo.

Portanto, analisar a capacidade do País em produzir inovação é fundamental não só para a dimensão do desenvolvimento econômico, mas também para a manutenção e para o aperfeiçoamento da democracia e de suas instituições.

A experiência das chamadas economias de industrialização recente (Kim; Nelson, 2005, p. 12) como é o caso de Hong Kong, Coréia do Sul, Taiwan e Cingapura reforça que não há um caminho ideal único, ou seja, cada caso deve ser analisado de acordo com a sua realidade e especificidades. De acordo com Lall (2005, p. 91) "[...] muitos outros elementos críticos da estratégia podem diferir, e são estes que 
determinam as estruturas industriais e as bases tecnológicas resultantes". No entanto, existem algumas questões que devem ser comuns para todos os casos: criação de capital humano, sistemas eficientes de amparo à tecnologia, acesso a novas tecnologias e estreitos contatos com mercados mundiais (Lall, 2005, p. 91).

$\mathrm{Na}$ perspectiva brasileira, não só a análise do Marco Civil da Internet é relevante, mas também ganha importância a análise dos elementos do ordenamento jurídico nacional que regulam a inovação.

Em outras palavras, é preciso verificar se o ordenamento jurídico nacional apresenta características que auxiliam a criação de sistemas de inovação e se as modificações recentes são capazes de auxiliar o País a construir iniciativas como a dos EUA, Europa, China, entre outros.

Destaca-se, portanto, a Emenda Constitucional $n^{\circ} 85$ de 26 de fevereiro de 2015 e a Lei $\mathrm{n}^{\circ} 13.243$ de 11 de janeiro de 2016, chamada de Novo Marco Legal da Ciência, Tecnologia e Inovação. Dada a recente elaboração e implementação, tratamse de instrumentos que precisam ser analisados, pois, estes irão desenhar o Sistema de Inovação no âmbito nacional. Além de se verificar o papel de cada ator neste sistema, destacando-se principalmente o papel do Estado brasileiro.

0 presente estudo é apresentado como um ensaio crítico sobre a atual estrutura normativa de Ciência, Tecnologia e Inovação no Brasil. Pretende-se a partir deste ensaio contribuir para o entendimento do atual contexto, analisando as bases teóricas que suportaram a sua implementação.

Nestes termos, o objetivo geral do presente estudo é o de desvelar a matriz, as concepções e objetivos por trás da nova estrutura normativa mencionada e suas principais características.

\section{SISTEMA DE INOVAÇÃO SEGUIDO NO CASO BRASILEIRO}

Após a Segunda Guerra Mundial, as experiências de sistemas de inovação se proliferaram a nível mundial (EUA em 1950; Europa e Japão em 1970; Ásia e Pacífico em 1980). Estes ambientes de inovação se consolidaram como um instrumento de fortalecimento do capital humano-empreendedor, capaz de suprir a demanda de inovação do mercado globalizado e da nova economia do conhecimento.

O surgimento destes sistemas é marcado pela convergência de diversos fatores e com características distintas. No entanto, na sua receita básica identifica-se a pesquisa científica e tecnológica desenvolvida nas universidades e nas Instituições de Ciência e Tecnologia, bem como no fomento dos órgãos e agências estatais e no empreendedorismo das empresas. Ou seja, a aliança entre Universidade, Governo e Empresas (Triple Helix University Industry Government Relations) é, portanto, a receita básica para o desenvolvimento de um ecossistema de inovação.

Em todas essas experiências, em diferentes graus e dimensões de participação ou fomento, a figura do Estado foi fundamental. Etzkowitz (2013) classifica os sistemas de tripla hélice em regime estatista e regime laissez-faire, mas destaca que o Estado tem ocupado significativo papel em ambos.

Isto pode ser demonstrado numa rápida análise da inovação nos Estados Unidos, pois, segundo Etzkowitz (2013, p. 20), mesmo nos EUA, onde a sociedade está estritamente ligada ao sentimento de laissez-faire, as esferas institucionais estão mais próximas do que se espera.

Mazzucato (2014, p. 95) também desvela o papel do Estado nesses sistemas destacando que nos EUA os gastos governamentais em pesquisa básica correspondem a $57 \%$ enquanto o setor privado assume 18\%. Mesmo analisando os gastos em Pesquisa e Desenvolvimento (P\&D), onde os recursos governamentais correspondem a $26 \%$ e os gastos privados a $67 \%$, a autora expõe que por trás da General Purpose Technologies (GPTS) existe sempre o investimento governamental. 
Assumindo não só os investimentos na pesquisa básica e fundamental para a estruturação da inovação, mas também boa parte do investimento de risco e cita o caso da internet e a estruturação do sistema de inovação do Vale do Silício.

Por sua vez, Etzkowitz (2013) menciona que durante a crise da década de 1970 e 1980 os EUA criaram um sistema público de capital de risco para transformar as pesquisas em produtos e relata que:

Uma parcela relativamente pequena das despesas em pesquisa estava realmente sendo traduzida em produtos, mesmo considerando-se um período prolongado. Para resolver esse problema os EUA criaram um sistema público de capital de risco como uma extensão da pesquisa básica. Ele não poderia ser chamado de capital de risco público, mas os executivos do Programa da National Innovation Research (SBIR) Reconheceram que uma terminologia neutra de etapas e fases tinha que ser utilizada" (ETZKWITZ, 2013, p. 95).

Este papel continua sendo desempenhado nos dias atuais e pode ser verificado no exemplo do desenvolvimento da energia solar nos EUA. Mazzucato cita o caso da First Solar:

\begin{abstract}
O sucesso de empresas como a First Solar nos Estados Unidos, por exemplo, foi construído ao longo de várias décadas, nas quais o capital de risco entrou em um estágio relativamente tardio e saiu logo depois de concluída a primeira oferta pública inicial (IPO) das ações. A maior parte do risco do investimento na first solar foi bancada pelo governo americano, que apoiou o desenvolvimento e a comercialização de sua inovadora tecnologia solar de película fina chegando ao ponto de ajudar no desenvolvimento do processo de fabricação" (MAZZUCATO, 2014, p. 178).
\end{abstract}

Outros exemplos de atuação do Estado norte-americano na inovação, em diferentes fases do processo são a Agência de Projetos de Pesquisa Avançada de Defesa (DARPA), o Programa de Pesquisa para a Inovação em Pequenas Empresas (SBIR), o Orphan Drug Act e a National Nanotechnology Initiative (INICIATIVA NACIONAL DE NANOTECNOLOGIA, 2017).

Estes instrumentos legais e agências atuam desde o financiamento da pesquisa básica até a produção de produtos e fazem com que o papel do Estado nos EUA seja a de um agente protagonista no processo de inovação (MAZZUCATO, 2014).

Em suma, verifica-se que num Sistema de Inovação em que se apresentam resultados significativos, como o caso do sistema norte americano, a presença do Estado é fundamental. No que se refere à inovação, a matriz de pensamento que orienta as políticas governamentais possui uma boa dose de intervencionismo e de influência do pensamento de Keynes em prejuízo a uma postura mais próxima ao laissez-faire.

A visão keynesiana coloca o Estado como um importante instrumento na efetivação de políticas contra cíclicas, estimulando as demandas de investimento para a recuperação da economia capitalista. Mas tanto Mazzucato (2014) como Etzkowitz (2013) destacam que o papel do Estado na inovação parece ultrapassar a fronteira que o liberalismo e que a própria visão keynesiana estabelecem entre o papel do público e do privado. Desta forma, criando uma fusão de esforços para atingir um objetivo comum entorno do desenvolvimento e produção de uma inovação.

No Brasil, a interface entre o setor público e o setor privado encontra obstáculos, muitos deles, representados no ordenamento jurídico nacional que impede a articulação entre os dois setores, identificando-a como uma espécie de 
risco aos recursos públicos. Segundo um estudo técnico elaborado pela assessoria da Câmara dos Deputados (Nazareno, 2016) as mudanças legislativas tentaram desburocratizar e descentralizar as ações na área de Ciência, Tecnologia e Inovação (CTI). No entanto, foram além e adotaram uma matriz de sistema de inovação de tripla hélice típica, dando ao Estado um papel central na articulação do sistema.

Esse papel fica nítido não só na análise da Lei $n^{\circ} 13.243$ de janeiro de 2016, mas principalmente na Emenda Constitucional $n^{\circ} 85$ de fevereiro de 2015. Ambos trouxeram novos institutos e conceitos jurídicos que, em síntese, tem por objetivo reestruturar a área de Ciência, Tecnologia e Inovação no Brasil através de três eixos principais:

a) criar um sistema nacional de Ciência Tecnologia e Inovação;

b) integrar o setor privado e o setor público e;

c) a simplificação de processos administrativos, orçamentários e financeiros do Estado na área de CTI.

Estas modificações trazem forte influência de uma concepção de sistema de inovação de tripla hélice e colocam o Estado e suas instituições como elemento estruturante do processo.

A perspectiva da mudança normativa é fundamental ao processo de aplicação de novos dispositivos normativos, principalmente para os órgãos de controle como a Controladoria Geral da União e o Tribunal de Contas da União, bem como para os próprios órgãos jurisdicionais.

\section{OS NOVOS MARCOS LEGAIS DA CIÊNCIA, TECNOLOGIA E INOVAÇÃO NO BRASIL}

O novo marco legal da CTI normatizou um modelo de sistema de inovação nacional caracterizado como um modelo de tripla hélice, mas estruturado a partir do Estado.

No amplo debate que antecedeu a aprovação da Emenda Constitucional $\mathrm{n}^{\circ}$ 85 e a Lei $n^{\circ} 13.243 / 2016$, com a representação dos segmentos mais importantes da sociedade, do mercado e do próprio Estado ${ }^{1}$ o Brasil não caiu em falsas contradições entre perspectivas liberais ou estatistas, para usar as categorias de Etzkowitz (2013). O País, claramente, colocou o Estado como elemento estruturador e articulador de um sistema, mas estabeleceu esse papel em conjunto com a sociedade civil e o mercado dentro de uma conjuntura democrática.

Assim ficou estabelecido numa das principais alterações trazidas pela Emenda Constitucional $\mathrm{n}^{\circ}$ 85, ao dar nova redação ao artigo 218 da Magna Carta, que o Estado promoverá e incentivará o desenvolvimento científico, a pesquisa científica, a pesquisa a capacitação cientifica e tecnológica e a inovação.

O novo texto constitucional é cuidadoso, pois, ao mencionar este conjunto de palavras estipula a presença do Estado como agente incentivador e promotor presente numa espécie de itinerário que vai desde a pesquisa básica, passa pela capacitação de pessoal e acaba na inovação.

Percebe-se, a partir de leitura sistemática, ou seja, a interpretação do texto constitucional deve ser feita em conjunto com os dispositivos inseridos pela Lei $\mathrm{n}^{\circ}$ 13.243/2016, que os novos dispositivos normativos criaram um itinerário da inovação e estabeleceram a participação do Estado nesse itinerário. Nesse caso, o

\footnotetext{
${ }^{1}$ Destaca-se as principais entidades que participaram da discussão: a Sociedade Brasileira para o Progresso da Ciência (SBPC), a Associação Nacional de Pesquisa e Desenvolvimento das Empresas Inovadoras (ANPEI), a Associação Nacional dos Dirigentes das Instituições Federais de Ensino Superior (ANDIFES), o Conselho Nacional das Fundações Estaduais de Amparo à Pesquisa (CONFAP), entre outras.
} 
artigo 218 da Magna Carta estabelecendo os parâmetros gerais e a Lei $n^{\circ}$ 13.243/2016 definindo de forma mais específica o regramento já partir do seu artigo $1^{\circ}$ e definindo várias categorias jurídicas no artigo $2^{\circ}$, dentre elas a inovação em seu inciso $\mathrm{V}$.

Como mencionado anteriormente, este papel atribuído ao Estado não é uma criação do legislador nacional, mas sim um modelo mundial de sistema de inovação que está por trás das GTPS. Mazzucato (2014) comenta que existe um "Estado por trás do iPhone", afirmando que além do "espírito louco de Steve Jobs" também ocorrerão investimentos enormes do Estado em tecnologias que sustentam o iPhone, como a internet, o GPS, telas sensíveis ao toque (touch-screen), e tecnologias de comunicação. Além dos investimentos estatais realizados na própria produção na década de 70 e 80, como capital de risco (MAZUCATTO, 2014, p. 127).

Este caso exemplifica o objetivo de se estabelecer um sistema a partir da atuação do Estado, ou seja, o que a norma determina é a atuação do Estado em áreas em que tradicionalmente ele não atua. Os órgãos jurisdicionais, o Executivo e mesmo os órgãos de controle devem levar em consideração esse fundamento na aplicação desses novos marcos legais que transformam a atuação do Estado e dele exigem agilidade, eficiência e empreendedorismo. Elementos estranhos à cultura jurídica nacional e conceitos da área de CTI devem ser assimilados em prol do desenvolvimento científico e tecnológico do País.

Estes elementos ficam ainda mais claros na nova redação dos artigos, 23, inciso V, 24, inciso IX, $167 \S 5^{\circ}, 213 \S 2^{\circ}, 219-A, 219-B$ e no parágrafo único do artigo 219 da Constituição Federal.

A nova redação do artigo $167 \S 5^{\circ}$, por exemplo, rompe com uma tradição jurídica inaugurada com a Lei $\mathrm{n}^{\circ} .4 .320$, de 17 de março de 1964 e que foi alçada ao status de lei complementar pela jurisprudência nacional. Qual seja a de impedir o Poder Executivo de efetuar transposição, remanejamento ou transferência de recursos de uma categoria de programação para outra ou de um órgão para outro sem a autorização do Poder Legislativo.

Em termos práticos, esta orientação limitava a atuação da Administração e exigia um grau de planejamento exaustivo, incompatível com a natureza de um projeto de desenvolvimento na área de ciência, tecnologia e inovação. Nesta área, a imprevisibilidade de resultados e a mudanças de rumos em projetos complexos necessitam de maior agilidade de órgãos que dele participam, seja como agente financiador, seja como agente executor.

Assim, a nova redação do parágrafo $5^{\circ}$ do artigo 167 da $\mathrm{CF}$, bem como a

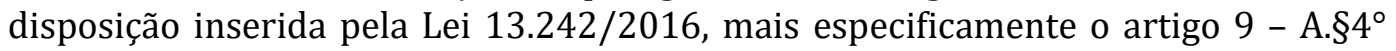
flexibiliza a aplicação de recursos públicos na área de CTI permitindo transposição, remanejamento ou transferência de recursos de categoria de programação para outra.

Um exemplo prático disto é a possibilidade de utilização de recursos originalmente prevista para custeio, como bolsas de pesquisadores, em investimento, como a compra de equipamentos de laboratório para suprir necessidades advindas no decorrer do projeto.

A nova redação dos artigos 23 , inciso $V$ e 24 , inciso IX, descentralizam para Estados e Municípios a competência para legislar sobre temas de CTI, buscando o fomento da área em diferentes regionalidades.

No parágrafo único do artigo 219 e no artigo 219-A o novo texto constitucional determinado pela Emenda n. 85, reforça a atuação do Estado no fortalecimento da inovação nas empresas além de estabelecer outras categorias que serão definidas na Lei n. 13.243/2016, como parques tecnológicos, transferência de tecnologia, entre outros.

0 texto constitucional demonstra, especificamente, nesta parte e seguindo um itinerário do processo de inovação, que vai da pesquisa básica à colocação do 
produto ou serviço no mercado como no exemplo norte-americano, a autorização para que o Estado atue no mercado e mesmo em empresas privadas.

Em sequência lógica, as alterações trazidas pela Lei n. 13.243/2016 trazem uma série de dispositivos que irão regrar essa autorização Constitucional para a atuação do Estado, mas o maior exemplo é o artigo 5 da Lei no 10.973/2014². Esse dispositivo permite que a União, Estados e Municípios possam participar, minoritariamente, do capital social de empresas. Assim como nos Estados Unidos, o legislador nacional pretendeu autorizar o Estado a participar do processo de inovação não só nas suas fases iniciais, mas também na sua fase de inserção no mercado.

Destaca-se também o compartilhamento de instalações e de capital intelectual com ou sem contrapartida financeira, o que amplia significativamente as possibilidades de interação entre o Estado, suas instituições de ciência, tecnologia e inovação e empresas privadas.

Em outras palavras, as empresas envolvidas no desenvolvimento ou mesmo na inserção de inovações no mercado podem acessar não só a infraestrutura de uma ICT pública, bem como trabalhar em conjunto com seu pessoal técnico e acessar o conhecimento produzido.

Já o artigo 219-B insere um elemento fundamental, qual seja, o conceito de sistema de ciência, tecnologia e inovação integrando o Estado, o mercado e as instituições de ciência, tecnologia e inovação.

Embora o parágrafo primeiro remeta a ideia de uma regulamentação do Sistema Nacional de CTI, muitas categorias jurídicas e traços estruturantes do sistema já foram normatizados, ou seja, a Lei no 13.243/2016 estabeleceu as regras para a efetivação desse sistema de Ciência, Tecnologia e Inovação no Brasil.

Para esse objetivo, o referido dispositivo normativo perpassa uma série de outras leis, alterando-as (NAZARENO, 2016), conforme segue:

a) Lei de Inovação (10.973/04).

b) Estatuto do Estrangeiro (6.815/80) - objetiva incluir visto temporário para pesquisador.

c) Lei de Licitações (8.666/93) - dispensa de licitações para produtos de CTI.

d) Lei de Regime Diferenciado de Contratações Públicas - RDC (12.462/11).

e) Lei de Contratação Temporária no Serviço Público - possibilita a contratação de técnicos em ICT.

f) Lei de relações entre as Universidades (8.958/94).

g) Lei de Importação (8.032/90) - importação com isenção de impostos para ICT.

h) Plano de Carreira das Universidades (12.772/12) - Flexibiliza a relação dos professores com as Instituições.

Em suma, a emenda constitucional $\mathrm{n}^{\circ} 85 / 2015$ e a Lei $\mathrm{n}^{\circ} 13.243 / 2016$ criaram uma nova matriz normativa para a área de ciência, tecnologia e inovação. Introduzindo categorias jurídicas e conceitos que deverão ser absorvidos pelos órgãos jurisdicionais, órgãos de controle e doutrina para que o País possa ter efetivamente um sistema nacional de CTI.

\footnotetext{
${ }^{2}$ Art. 5o - São a União e os demais entes federativos e suas entidades autorizados, nos termos de regulamento, a participar minoritariamente do capital social de empresas, com o propósito de desenvolver produtos ou processos inovadores que estejam de acordo com as diretrizes e prioridades definidas nas políticas de ciência, tecnologia, inovação e de desenvolvimento industrial de cada esfera de governo.
} 


\section{CONSIDERAÇÕES FINAIS}

As instituições do Estado Democrático de Direito precisam se adaptar às transformações que as inovações tecnológicas trazem. Os desafios dessa nova conjuntura não exigem apenas novas normas, mas também de meios ou instrumentos tecnológicos que possam dar efetividade ao papel dessas instituições.

Como é possível perceber, democratizar a inovação ou mesmo ter inovações a serviço da democracia exige um ordenamento jurídico e um sistema de CTI estruturados e articulados.

0 primeiro tem que ser capaz de criar um arcabouço normativo que permita ao Estado desempenhar o seu papel de protagonista no desenvolvimento de GPTS (General Purpose Technologies), como no exemplo de sistema de inovação bemsucedido norte-americano.

O segundo deve produzir inovações alinhadas com os princípios do Estado Democrático de Direito promovendo o desenvolvimento econômico e social do País.

A emenda constitucional $n^{\circ} 85 / 2015$ e a Lei 13.243/2016 trazem esse objetivo, qual seja, de estabelecer uma base normativa para a criação de um sistema de inovação de hélice-tripla estruturado a partir do Estado, mas em uma conjuntura democrática.

Verifica-se também, que os dispositivos não limitaram o papel do Estado à pesquisa básica ou ao fornecimento de infraestrutura para projetos de inovação. Sua presença é permitida em todo o itinerário de um projeto de inovação, podendo alcançar a sua fase final, qual seja, a sua introdução no mercado. Podendo, para tanto, atuar em conjunto ou mesmo fazendo parte do capital social de empresas privadas.

Ficam nítidos, portanto, os objetivos e mesmo a concepção das alterações trazidas pelos novos marcos legais de CTI. Estes podem ser resumidos sinteticamente na criação de um sistema de CTI, estruturação através do Estado e sua articulação com os agentes de privados. Torna-se necessário acompanhar a sua aplicação pelos órgãos jurisdicionais, órgãos de controle e mesmo pelo Poder Executivo para verificar a implantação do Sistema Nacional de Inovação com essas características.

Desta forma, significa dizer que o Sistema de Ciência, Tecnologia e Inovação Nacional está desenhado no campo normativo, mas um ajuste contínuo e a análise dos seus resultados é um exercício a ser feito com rigor e atenção.

\section{REFERÊNCIAS}

ABREU, M. C.; MASETTO, M. T. o professor universitário em sala de aula. São Paulo: Cortez, 1980.

CAMPBEL, J. L. Ideas, Politics and Public Policy. Annual Review of Sociology, v. 28, p. 21-28, 2002.

DENISON, E. F. The Sources of Economic Growth in the United States and the Alternatives before Us. Committee for Economic Development, 1962.

BRASIL. Congresso Nacional. Lei no 10.973, de 2 de dezembro de 2004. Disponível em: $<$ http://www.planalto.gov.br/ccivil 03/ ato2004-2006/2004/lei/110.973.htm>. Acesso em: 03 de jul. de 2017.

BRASIL. Congresso Nacional. Lei no 13.243, de 11 de janeiro de 2016. Disponível em: <http://www.planalto.gov.br/ccivil 03/ ato2015-2018/2016/lei/l13243.htm>. Acesso em: 03 de jul. de 2017. 
BRASIL. Congresso Nacional. Emenda Constitucional $\mathbf{n}^{\circ}$ 85, de 26 de fevereiro de 2015. Disponível em:

<http://www.planalto.gov.br/ccivil 03/constituicao/emendas/emc/emc85.htm>. Acesso em: 03 de jul. de 2017.

JUNQUEIRA, E. B. A sociologia do direito no Brasil. Rio de Janeiro: Lumen Juris, 1993.

KEYNES, J. M. O Fim do "Laissez-Faire”. In: SZMRECSANY, T.; KEYNES, J. M. Economia. São Paulo, 1983.

KIM, L.; NELSO, R. R. Tecnologia, Aprendizado e Inovação: A experiência das Economias de Industrialização Recente. Editora da Unicamp: Campinas, 2005.

LAMPERT, E. Educação para a cidadania: gênero, etnia, políticas educacionais, competência docente/discente. Porto Alegre: Sulina, 1999.

MARX, K. Capital. Modern Library: New York, 1867.

MAZZUCATO, M. O estado empreendedor: desmascarando o mito do setor público vs. Privado. Trad. por Elvira Serapicos. $1^{\mathfrak{a}}$ ed. São Paulo: Portfólio-Penguin, 2014.

MOREIRA, D. A. Didática do ensino superior: técnicas e tendências. São Paulo: Pioneira, 1996.

MORIN, E. Os sete saberes necessários à educação do futuro. Trad. por Catarina Eleonora. 3a ed. São Paulo: Cortez, 2001.

NAZARENO, C. As mudanças promovidas pela Lei $n^{\circ}$ 13.243, de 11 de janeiro de 2016 (novo marco legal de ciência, tecnologia e inovação) e seus impactos no setor. Estudo Técnico da Câmara dos Deputados. Brasília: Câmara dos Deputados, 2016.

NETO, E. J. M.; MORAIS, J. L. B. A Insuficiência do marco civil da internet na proteção das comunicações privadas armazenas e do fluxo de dados a partir do paradigma da Surveillance. In: LEITE, G. S.; LEMOS, R. (org.). Marco Civil da Internet. São Paulo: Atlas, 2014.

SCHUMPETER, J. A. The Theory of Economics Development. Harvard University Press: Cambridge, 1968. [publicado pela primeira vez em 1911].

SOLOW, R. M. Technical Change and the Aggregate Production Function. Review of Economics and Statistics, v. 39, p. 312-320, 1957. 